\title{
TERAPI WELL-BEING UNTUK MENINGKATKAN PSYCHOLOGICAL WELL-BEING PADA REMAJA YANG TINGGAL DI PANTI SOSIAL BINA REMAJA $X$
}

\author{
Ivon Hartato, Debora Basaria ${ }^{1}$, Soemiarti Patmonodewo \\ Fakultas Psikologi Universitas Tarumanagara \\ ${ }^{1}$ deborab@fpsi.untar.ac.id
}

\begin{abstract}
The purpose of this research is to know the application of Well-Being Therapy (WBT) in increasing psychological well-being of adolescents who live in PSBR X. This research used pre-experimental one group pretest-posttest design, the score of psychological well-being from the participants will measured at the beginning and at the end of WBT, using Ryff psychological well-being scale. Participants of this research are two adolescents, 16 to 18 years old, and live in PSBR X within six months. WBT conducted in six sessions, about 60 minutes in each session. The result of the research showed that the psychological well-being of two participantsincreased after finished the WBT. This prove that WBT can increase psychological well-being of adolescents who live in PSBR X.
\end{abstract}

Keywords: well-being therapy, psychological well-being, adolescents, social institution

\begin{abstract}
ABSTRAK
Penelitian ini dilakukan untuk mengetahui penerapan Well-Being Therapy (WBT) dalam meningkatkan psychological well-being remaja yang tinggal di PSBR X. Penelitian ini menggunakan desain preeksperimental one group pretest-posttest design, yaitu peneliti akan mengukur skor psychological wellbeing subyek, sebelum dan sesudah mengikuti WBT. Penelitan ini menggunakan alat ukur adaptasi dari Ryff psychological well-being. Subyek penelitian adalah dua orang remaja berusia 16 hingga 18 tahun dan tinggal di Panti Sosial Bina Remaja X dalam waktu kurang dari enam bulan. Intervensi dengan WBT dilakukan sebanyak 6 sesi dengan durasi selama kurang lebih 60 menit setiap sesi. Hasil penelitian menunjukkan bahwa kedua subyek menunjukkan peningkatan psychological well-being setelah mengikuti WBT. Hal ini menunjukkan bahwa WBT memiliki peranan dalam meningkatkan psychological wellbeing remaja yang tinggal di Panti Sosial Bina Remaja X.
\end{abstract}

Kata kunci: terapi well-being, psychological well-being, remaja, institusi sosial

\section{PENDAHULUAN}

\subsection{Latar Belakang}

Masa remaja merupakan waktu untuk bertumbuh, berpindah dari ketidakdewasaan masa kanak-kanak menuju kedewasaan pada masa dewasa, serta masa di mana individu mempersiapkan diri menuju masa depan (Larson, Wilson, \& Rickman; Schlegel dalam Steinberg, 2011). Menurut Harvigurst (dalam Sarwono, 2011), beberapa tugas perkembangan yang harus dipenuhi oleh remaja, antara lain menerima kondisi fisiknya dan memanfaatkan tubuhnya secara efektif, menerima hubungan yang lebih matang dengan teman sebaya dan lawan jenisnya, menerima peran gender masing-masing, mempersiapkan karir dan kehidupan keluarga (Santrock, 2012).

Transisi yang dialami remaja bersifat kompleks dan terjadi dalam berbagai dimensi, melibatkan perubahan di berbagai aspek kehidupan individu. Hal ini membuat remaja membutuhkan faktor-faktor pendukung yang dapat membantunya memenuhi tugas-tugas perkembangan yang dimiliki (Santrock, 2012). Faktor-faktor yang memengaruhi perkembangan remaja, antara lain faktor hereditas dan faktor lingkungan; serta fasilitas-fasilitas yang ada dalam lingkungan (Gunarsa \& Gunarsa, 
2012). Apabila remaja gagal atau mengalami hambatan dalam pemenuhan kebutuhan, maka remaja akan mengalami kesulitan pada tahapan perkembangan selanjutnya (Sari, 2015). Remaja yang mengalami kegagalan dalam sekolahnya, tinggal di lingkungan yang cenderung negatif, kondisi sosial ekonomi yang kurang baik, ataupun keluarga yang kurang memberikan perhatian dan dukungan, menjadi rentan terkena stress dan dapat terjerumus ke dalam permasalahan remaja (Sari, 2015).

Melihat permasalahan sosial yang seringkali dialami oleh remaja, Dinas Sosial menyelenggarakan sebuah program yang dapat membantu para remaja, yaitu dengan membentuk sebuah panti sosial khusus untuk remaja. Lembaga pelayanan sosial seperti Panti Sosial Bina Remaja (PSBR) adalah panti sosial yang mempunyai tugas memberikan bimbingan, pelayanan dan rehabilitasi bagi anak terlantar putus sekolah agar mampu mandiri dan berperan aktif dalam kehidupan bermasyarakat (Kepmensos No.50/HUK/2004). Selain itu, pembekalan yang diberikan dapat berguna untuk memperbaiki kualitas hidup maupun ekonominya di kemudian hari.

PSBR X merupakan salah satu panti sosial bina remaja yang terletak di daerah Jakarta Selatan. Para remaja yang tinggal di Panti Sosial Bina Remaja (PSBR) X ini berasal dari latar belakang dan permasalahan sosial yang berbeda-beda, ada yang sebelumnya hidup di jalan sebagai gelandangan, anak-anak yang putus sekolah, ada yang ditertibkan oleh petugas Dinas Sosial saat sedang mengamen, mengemis dan sebagainya. Para remaja akan menjalani rehabilitasi sosial. Para petugas dan pihak panti berusaha membantu dengan memberikan pelayanan yang terbaik bagi para remaja yang tinggal di panti, yaitu dengan diberikan berbagai fasilitas, seperti tempat tinggal, pakaian, makanan, pelatihan keterampilan, bimbingan keagamaan, dan pembinaan lainnya. Di PSBR X ini, para remaja ini diberikan pendidikan non-formal, berupa keterampilan sesuai dengan minat dan kemampuannya, antara lain keterampilan salon, menjahit, servis $\mathrm{AC}$, handphone, dan mengelas.

Meskipun telah disediakan berbagai fasilitas fisik yang memadai, para remaja seringkali masih merasa tidak nyaman, merasa bahwa kehidupan di luar itu lebih bebas dan tidak dituntut tanggung jawab, dan beberapa remaja pun akhirnya melarikan diri dari panti. Remaja juga masih seringkali melakukan pelanggaran, butuh teguran untuk mau mengikuti aktivitas di panti dengan baik. Secara mental, para remaja masih seringkali lebih ingin menjalani kehidupan yang bebas di jalan, tanpa memikirkan lebih lanjut masa depan yang ingin dirangkai.

Pihak panti terus berupaya untuk membangun mental dan mengubah mindset para remaja yang sedang berada dalam proses pembinaan. Berbagai kegiatan pembinaan dilakukan untuk mengubah para remaja yang sebelumnya tidak mempunyai motivasi, tidak mempunyai cita-cita atau keinginan, tidak bertanggung jawab, dan tidak disiplin menjadi lebih baik. Hal ini ditujukan untuk mendorong para remaja untuk memiliki masa depan yang lebih baik dan hidup yang lebih layak. Kegiatan yang dilakukan oleh pihak panti, merupakan salah satu cara yang dilakukan untuk meningkatkan keberfungsian hidup dan membangun pandangan yang positif dari para remaja, yang dalam istilah psikologis dapat dikaitkan dengan psychological wellbeing.

Huppert (dalam Winefield, Gill, Taylor, \& Pilkington, 2012) mengungkapkan secara singkat bahwa psychological well-being berkaitan dengan kehidupan yang dianggap berjalan dengan baik. Individu yang memiliki psychological well-being yang tinggi menampilkan adanya perasaan bahagia, merasa mampu, mendapat dukungan, puas dengan hidupnya, dan sebagainya. Melihat manfaat yang dapat diperoleh jika seseorang memiliki psychological well-being yang tinggi, maka pembentukan psychological well-being di masa remaja dapat menjadi salah satu hal penting yang perlu diperhatikan. Sari (2015) mengungkapkan bahwa remaja dapat memiliki psychological 
well-being tinggi dengan mengembangkan segala potensi yang dimiliki remaja dan berusaha mewujudkan cita-citanya. Remaja ingin memperoleh kesempatan untuk mengembangkan diri untuk mewujudkan jati diri. Penelitian yang dilakukan oleh Septiani (2013) terhadap sejumlah remaja yang tinggal di sebuah Panti Sosial Asuhan Anak di Jakarta menunjukkan bahwa jumlah remaja yang memperoleh skor psychological well-being di bawah rata-rata lebih banyak dengan jumlah remaja yang memiliki skor di atas rata-rata.

Salah satu intervensi yang telah terbukti cukup mampu dalam meningkatkan psychological well-being adalah well-being therapy. Folk-Williams (2013) mengungkapkan bahwa well-being therapy merupakan salah satu treatment psikologis yang tergolong baru. Well-being therapy sebagai satu bagian dari psikologi positif yang berusaha untuk membantu individu dengan meningkatkan aspek positif yang dimiliki serta mengembangkan kekuatan yang dimiliki tanpa menekankan pada aspek negatif yang dimiliki (Holland, 2007).

Berdasarkan hal tersebut, maka dilakukan penelitian ini, yang bertujuan untuk mengetahui penerapan well-being therapy dalam meningkatkan psychological well-being remaja yang tinggal di Panti Sosial Bina Remaja X. Penerapan intervensi ini diharapkan mampu membantu remaja dalam meningkatkan psychological well-being yang dimilikinya, agar remaja mampu menampilkan sikap positif terhadap dirinya dan kehidupannya. Kondisi ini dapat memberikan dampak positif bagi perkembangan remaja yang tinggal di PSBR, sehingga para remaja dapat lebih memotivasi dirinya sendiri, mengembangkan hal-hal positif dalam dirinya, dan mempersiapkan diri untuk masa depannya secara lebih baik. Rumusan masalah dari penelitian ini adalah bagaimana penerapan well-being therapy dalam meningkatkan psychological wellbeing remaja yang tinggal di Panti Sosial Bina Remaja X?

\subsection{Permasalahan}

Bagaimana penerapan well-being therapy dalam meningkatkan psychological well-being remaja yang tinggal di Panti Sosial Bina Remaja X?

\subsection{Tujuan Penelitian}

Tujuan dari penelitian ini adalah untuk mengetahui penerapan well-being therapy dalam meningkatkan psychological well-being pada remaja yang tinggal di panti sosial bina remaja.

\section{TINJAUAN PUSTAKA}

Gunarsa, Y. S. dan Gunarsa, S. D. (2012) memaparkan faktor-faktor yang memengaruhi proses perkembangan seseorang ke dalam dua kelompok utama, yaitu (1) faktor-faktor dalam diri individu sendiri, meliputi faktor-faktor endogen, yang terdiri dari komponen hereditas, yaitu keturunan dan faktor konstitusi; (2) faktorfaktor yang berasal dari luar individu, disebut dengan faktor eksogen, yang terdiri atas berbagai komponen lingkungan, seperti lingkungan keluarga, lingkungan sosial, dan lingkungan geografis) serta fasilitasfasilitas yang ada dalam lingkungan, seperti makanan dan kesempatan / stimulus belajar.

Panti sosial Bina Remaja adalah panti sosial yang mempunyai tugas memberikan bimbingan, pelayanan dan rehabilitasi bagi anak terlantar putus sekolah agar mampu mandiri dan berperan aktif dalam kehidupan bermasyarakat. (Kemensos No.50/HUK/ 2004 dalam http://www.kemsos.go.id/). Tugas pokok dari Panti Sosial Bina Remaja adalah melaksanakan pembinaan remaja yang bermasalah sosial (leaflet PSBR, 2015). Pembinaan yang dilakukan di PSBR X, meliputi pembinaan fisik dan kesehatan, pembinaan mental, pembinaan sosial, dan pelatihan keterampilan kerja usaha kemandirian. Keterampilan kerja yang diberikan adalah otomotif, las, menjahit, $\mathrm{AC} /$ pendingin, tata rias, service HP dan komputer, furniture, dan tata boga.

Psychological well-being adalah realisasi terhadap pencapaian penuh dari potensi individu. Individu dapat menerima segala kekurangan dan kelebihan dirinya, 
mandiri, mampu membina hubungan yang positif dengan orang lain. Individu juga dianggap mampu menguasai lingkungannya dalam arti mampu memodifikasi lingkungan agar sesuai dengan keinginannya, memiliki tujuan hidup, serta terus mengembangkan pribadinya. Psychological well-being dirumuskan ke dalam enam dimensi, yaitu (a) penerimaan diri, (b) hubungan positif dengan orang lain, (c) otonomi, (d) penguasaan lingkungan, (e) tujuan hidup, dan (f) pertumbuhan pribadi. (Ryff, 1989). Faktorfaktor yang dapat mempengaruhi psychological well-being pada diri individu, yaitu (a) usia, (b) gender, (c) status sosial ekonomi, (d) pendidikan, (e) budaya, (f) dukungan sosial, (g) kompetensi diri dan (h) kepribadian.

Well-being therapy merupakan salah satu treatment psikologis yang tercetus oleh beberapa tokoh psikologi positif, seperti Selligman, Fordyce, dan Padesky (Fava \& Tomba, 2009). Well-being therapy sebagai bagian dari psikologi positif berusaha untuk membantu individu dengan cara meningkatkan aspek positif yang dimiliki individu serta mengembangkan kekuatan yang dimiliki tanpa menitikberatkan pada aspek negatif yang mereka miliki (Holland, 2007). Pendekatan ini memusatkan pada proses yang dapat membangun kekuatan pada setiap individu untuk meningkatkan keberfungsian hidup mereka (Handler, 2008). Tujuan dari intervensi ini adalah untuk mengarahkan individu dari tingkat yang rendah ke tingkat optimal dalam keenam dimensi dari psychological wellbeing.

Well-being therapy adalah suatu strategi psikoterapi jangka pendek, yang diberikan dalam waktu 8-12 sesi, dan dilakukan setiap minggu (Fava \& Ruini, 2014). Durasi dari masing-masing sesi dapat berlangsung selama 30 sampai dengan 50 menit. Namun, jumlah dari sesi keseluruhan dapat disesuaikan dengan kebutuhan dan kondisi klien. Pada beberapa kasus, jumlah sesi dapat diperpendek sehingga memungkinkan bila tidak dilaksanakan sebanyak 8 kali pertemuan (Fava \& Ruini, 2003). Well-being therapy ini merupakan sebuah teknik yang menekankan observasi diri (Emmelkamp, 1974 dalam Fava \& Ruini, 2014), dengan penggunaan buku harian terstruktur, dan interaksi antara individu dan terapis. Sesisesi dalam well-being therapy, dapat dibagi dan dikembangkan dalam tiga bagian utama, yaitu sesi awal (initial sessions), sesi peralihan (intermediate sessions), dan sesi akhir (final sessions).

\section{METODE PENELITIAN}

Penelitian ini menggunakan metode penelitian kualitatif dan metode penelitian kuantitatif (mixed methods design). Tipe dari mixed methods design yang digunakan adalah exploratory mixed methods design. Exploratory mixed methods design merupakan metode penelitian yang menggunakan data kualitatif, dan menggunakan data kuantitatif sebagai pendukung (Vos, Strydom, Fouche, \& Delport, 2011).

\subsection{Subjek Penelitian}

Kriteria subjek dalam penelitian ini adalah (a) berada dalam kategori remaja akhir (16-18 tahun); (b) merupakan warga binaan sosial yang tinggal di Panti Sosial Bina Remaja X kurang dari enam bulan, (c) memiliki taraf kecerdasan di dalam kelompok average berdasarkan Culture Fair Intelligence Test 3A; (d) memiliki skor di bawah rata-rata pada satu atau lebih dimensi dari alat ukur psychological wellbeing.

\subsection{Desain Penelitian}

Desain penelitian yang digunakan adalah pre-eksperimental One Group Pretest-Posttest Design. Pada desain ini, di awal penelitian dilakukan pengukuran terhadap dependent variable pada partisipan, dalam penelitian ini yaitu psychological well-being remaja. Setelah diberikan manipulasi atau perlakuan, dilakukan pengukuran kembali terhadap dependent variable dengan alat ukur yang sama (Seniati, Yulianto, \& Setiadi, 2011). Pengambilan data penelitian dan intervensi well-being therapy akan dilaksanakan di 
Panti Sosial Bina Remaja X, yang terletak di daerah Jakarta Selatan.

\subsection{Pengukuran}

Pengukuran psychological well-being akan dilakukan dengan menggunakan alat ukur psychological well-being, wawancara dan observasi. Selain itu, untuk melengkapi profil subjek, dilakukan beberapa tes psikologis lainnya, yaitu tes inteligensi menggunakan Culture Fair Intelligence Test (CFIT 3A), tes grafis (DAM, BAUM, dan WZT), dan tes minat RMIB. Alat ukur psychological well-being (PWB) yang digunakan dalam penelitian ini merupakan alat ukur hasil adaptasi dari alat ukur psychological well-being yang dibuat oleh Carol D. Ryff (1996). Proses adaptasi dilakukan oleh bagian riset dan pengukuran Fakultas Psikologi Universitas Tarumanagara. Alat ukur yang digunakan terdiri dari 31 butir pernyataan dengan pilihan jawaban 'Tidak Setuju' (TS), 'Kurang Setuju' (KS), 'Agak Setuju' (AS), 'Setuju' (S), dan 'Sangat Setuju' (SS). Pada pernyataan positif, TS bernilai 1, KS bernilai 2 , AS bernilai $3, \mathrm{~S}$ bernilai 4 , dan SS bernilai 5. Sebaliknya, pada pernyataan negatif, TS bernilai 5, KS bernilai 4, AS bernilai 3, S bernilai 2, dan SS bernilai 1 . Setelah dilakukan skoring setiap butir, maka akan dilakukan penjumlahan untuk masing-masing dimensi, untuk dapat mengetahui tinggi rendahnya skor pada setiap dimensi. Uji validitas dan reliabilitas telah dilakukan terhadap alat ukur ini. Uji validitas dilakukan dengan menggunakan content validity dan construct validity.

Dimensi penerimaan diri (self acceptance) mengandung pengertian bahwa subjek cenderung memiliki sikap yang positif terhadap dirinya, mengenal dan menerima semua aspek yang ada dalam dirinya baik kelebihan dan kekurangannya, dan merasa positif dengan kehidupan masa lalunya (Haryanto \& Suyasa, 2007). Dimensi ini diukur dengan menggunakan 5 pernyataan yang terdiri dari 5 pernyataan positif. Hasil perhitungan reliabilitas internal dimensi penerimaan diri menghasilkan koefisien alpha cronbach sebesar 0,74 .
Dimensi hubungan positif dengan orang lain (positive relations with other) mengandung pengertian bahwa subjek mempunyai kecenderungan untuk merasa puas, hangat, memiliki hubungan saling percaya dengan orang lain, memperhatikan kesejahteraan orang lain, bersikap empati, penyayang, akrab, dan saling memberi dan menerima dalam hubungan manusia (Haryanto, R. \& Suyasa, P. T. Y. S., 2007). Dimensi ini memiliki 5 pernyataan yang terdiri dari 2 pernyataan positif dan 3 pernyataan negatif. Hasil perhitungan reliabilitas internal pada dimensi ini menghasilkan koefisien alpha cronbach sebesar 0,69. Dimensi otonomi (autonomy) memiliki pengertian bahwa subjek mampu mandiri, dapat bertahan dalam tekanan sosial, dapat mengatur perilakunya, dan menilai diri dengan standar pribadi (Haryanto, R. \& Suyasa, P. T. Y. S., 2007). Dimensi ini terdiri dari 4 pernyataan positif. Hasil perhitungan reliabilitas internal dimensi otonomi ini menghasilkan koefisien alpha cronbach sebesar 0,57.

Dimensi penguasaan lingkungan (environmental mastery) mengandung pengertian bahwa individu mampu menguasai dan mengolah lingkungan, dapat mengontrol kejadian di luar dirinya, menggunakan setiap kesempatan yang ada dengan efektif, dan dapat memilih keadaan yang sesuai dengan kebutuhan dan nilai yang dianut (Haryanto, R. \& Suyasa, P. T. Y. S., 2007). Dimensi ini memiliki 5 pernyataan, yang terdiri dari 1 butir positif dan 4 butir negatif. Hasil perhitungan reliabilitas internal pada dimensi penguasaan lingkungan ini menghasilkan koefisien alpha cronbach sebesar 0,66.

Dimensi pertumbuhan diri (personal growth) mengandung pengertian bahwa individu melihat dirinya terus bertumbuh dan berkembang, terbuka akan pengalaman baru, merealisasikan potensi yang dimilikinya, memperbaiki diri dan perilakunya terus menerus (Haryanto, R. \& Suyasa, P. T. Y. S., 2007). Dimensi ini diukur dengan menggunakan 5 pernyataan positif. Hasil perhitungan reliabilitas internal dimensi pertumbuhan diri 
menghasilkan koefisien alpha cronbach sebesar 0,70 .

Dimensi tujuan hidup (purpose in life) mengandung pengertian bahwa individu memperoleh tujuan dan arah hidup yang jelas, merasa bahwa hidupnya bermakna baik di masa lampau maupun yang dijalani saat ini, dan berpegang pada keyakinan yang menjadi tujuan hidupnya (Haryanto, R. \& Suyasa, P. T. Y. S., 2007). Dimensi ini diukur dengan menggunakan 7 pernyataan positif. Hasil perhitungan reliabilitas internal dimensi tujuan hidup menghasilkan koefisien alpha cronbach sebesar 0,61 .

\subsection{Prosedur Penelitian}

Prosedur penelitian dikelompokkan menjadi tiga bagian utama, yaitu persiapan penelitian, pengambilan data, dan pelaksanaan intervensi.

Tahap persiapan penelitian terdiri dari: mengamati dan mempelajari fenomena, mengunjungi panti sosial, mencari jurnal penelitian dan menyusun bab 1-3, dan mengurus surat izin ke PTSP.

Tahap pengambilan data terdiri dari: mengajukan karakteristik subjek, screening, pemeriksaan psikologis.

Tahap pelaksanaan intervensi terdiri dari: pre-test, enam sesi intervensi, dan post-test.

\section{HASIL DAN PEMBAHASAN}

Skor dari hasil pengukuran kuesioner PWB, menunjukkan bahwa SZ dan LH memiliki skor yang berada di bawah rata-rata kelompok. Selain itu, LH dan SZ juga memiliki taraf kecerdasan ratarata. Hal ini membuat $\mathrm{LH}$ dan SZ sesuai dengan kriteria subjek yang telah ditetapkan dan diberikan intervensi well-being therapy.

Tabel 1. Data Diri Subjek

\begin{tabular}{lcc}
\hline Keterangan & LH & SZ \\
\hline Jenis & Laki-laki & Perempuan \\
Kelamin & Jakarta, 31 & \\
Tanggal & Jakarta, 22 \\
lahir & $\begin{array}{c}\text { Desember } \\
\text { 1998 }\end{array}$ & Mei 2000 \\
Usia & 17 tahun 10 & 16 tahun 6 \\
bulan & bulan \\
\hline
\end{tabular}

\begin{tabular}{|c|c|c|}
\hline Agama & Islam & Islam \\
\hline $\begin{array}{l}\text { Pendidikan } \\
\text { terakhir }\end{array}$ & $\begin{array}{c}\text { Kelas XI ( } 2 \\
\text { SMA) }\end{array}$ & Lulus SMP \\
\hline $\begin{array}{l}\text { Tinggal di } \\
\text { panti sejak }\end{array}$ & Mei 2016 & $\begin{array}{c}\text { Oktober } \\
2016\end{array}$ \\
\hline $\begin{array}{l}\text { Alasan } \\
\text { tinggal di } \\
\text { panti }\end{array}$ & $\begin{array}{c}\text { Tidak } \\
\text { mengetahui } \\
\text { keberadaan } \\
\text { orangtua }\end{array}$ & $\begin{array}{c}\text { Putus } \\
\text { sekolah dan } \\
\text { perceraian } \\
\text { orangtua }\end{array}$ \\
\hline
\end{tabular}

Program intervensi dalam penelitian ini dilakukan dengan melalui beberapa tahapan. Tahap yang pertama adalah pemberian pre-test. Selanjutnya adalah sesisesi intervensi, yaitu menggunakan metode well-being therapy, yang akan berlangsung selama 6 kali pertemuan, yaitu dengan tahapan sebagai berikut (a) identifikasi, (b) pemahaman dan interpretasi, (c) restrukturisasi kognitif, (d) self-acceptance dan positive interpersonal relationship, (e) autonomy dan purpose in life, (f) happiness, evaluasi dan terminasi. Program intervensi kurang lebih akan berlangsung dalam waktu 3 minggu. Setelah itu, akan dilakukan evaluasi dan post-test untuk mengetahui hasil yang diperoleh dari pelaksanaan intervensi ini terhadap LH dan SZ, dan diakhiri dengan monitoring.

Tabel 2. Perbandingan Skor Pre-Test dan Post-Test pada Kedua Subjek

\begin{tabular}{|c|c|c|c|c|}
\hline \multirow{2}{*}{ Dimensi } & \multicolumn{2}{|c|}{$\begin{array}{c}\text { Subjek } 1 \\
\text { (LH) }\end{array}$} & \multicolumn{2}{|c|}{$\begin{array}{c}\text { Subjek } 2 \\
\text { (SZ) }\end{array}$} \\
\hline & $\begin{array}{l}\text { Pre- } \\
\text { test }\end{array}$ & $\begin{array}{l}\text { Pos- } \\
\text { ttest }\end{array}$ & $\begin{array}{c}\text { Pre- } \\
\text { test }\end{array}$ & $\begin{array}{r}\text { Post- } \\
\text { test }\end{array}$ \\
\hline $\begin{array}{c}\text { Self } \\
\text { Acceptance }\end{array}$ & 3.4 & 4 & 3.6 & 4 \\
\hline $\begin{array}{c}\text { Positive } \\
\text { relations- } \\
\text { with others }\end{array}$ & 2.8 & 3.4 & 3 & 3.2 \\
\hline Autonomy & 3.25 & 4 & 3.75 & 3.75 \\
\hline $\begin{array}{c}\text { Environ- } \\
\text { mental } \\
\text { mastery }\end{array}$ & 2.4 & 2.8 & 2.8 & 3.2 \\
\hline $\begin{array}{c}\text { Personal } \\
\text { Growth }\end{array}$ & 4 & 4.4 & 3.2 & 4 \\
\hline $\begin{array}{c}\text { Purpose in } \\
\text { life }\end{array}$ & 2.8 & 4.1 & 2.7 & 3.71 \\
\hline
\end{tabular}

Subjek 1 (LH) menampilkan adanya peningkatan skor pada keenam dimensi dari 
psychological well-being ini, yaitu selfacceptance, positive relations with others,autonomy, environmental mastery, personal growth, dan purpose in life. Berdasarkan analisis yang dilakukan dengan menggunakan uji perbedaan paired sample t-test, LH menampilkan adanya perbedaan nilai mean pre-test dari sebesar 3.10 dan mean post-test sebesar 3.78. Dari perbandingan nilai rata-rata tersebut terlihat bahwa skor psychological well-being yang ditampilkan LH pada saat sebelum dan sesudah intervensi mengalami peningkatan. Selanjutnya, dari hasil uji perbedaan mean diperoleh nilai $\mathrm{t}=-4.946, \mathrm{p}=0.004<0.05$, maka dengan demikian ada perbedaan signifikan antara nilai pre-test dan post-test pada subjek LH.

Pada subjek kedua, yaitu SZ menampilkan adanya peningkatan dalam lima dari enam dimensi dari psychological well-being, yaitu self-acceptance, positive relations with others, environmental mastery, personal growth, dan purpose in life. Sedangkan, dimensi autonomy menunjukkan skor yang tetap antara pretest dan post-test. Berdasarkan analisis yang dilakukan dengan menggunakan uji perbedaan paired sample t-test, SZ menampilkan adanya perbedaan nilai mean pretest dari sebesar 3.17 dan mean post-test sebesar 3.64. Dari perbandingan nilai ratarata tersebut terlihat bahwa skor psychological well-being yang ditampilkan SZ pada saat sebelum dan sesudah intervensi mengalami peningkatan. Selanjutnya, dari hasil uji perbedaan mean diperoleh nilai $\mathrm{t}=-3.057, \mathrm{p}=0.028<0.05$, maka dengan demikian ada perbedaan signifikan antara nilai pre-test dan post-test pada subjek SZ.

Monitoring dan evaluasi dilakukan untuk mengetahui perilaku kedua subjek, yaitu LH dan SZ dalam aktivitas sehari-hari setelah selesai mengikuti intervensi, sehingga dapat memperoleh gambaran tentang apakah kedua subjek menampilkan adanya perubahan perilaku yang positif, terutama dalam kaitannya dengan domaindomain dari psychological well-being. Proses monitoring dan evaluasi dilakukan satu minggu setelah kedua subjek menyelesaikan keenam sesi intervensi, yaitu pada Rabu, 21 Desember 2016. Peneliti menghubungi salah seorang pembina di Panti Sosial Bina Remaja X untuk mengetahui perilaku LH dan SZ akhir-akhir ini.

Pembina menyampaikan bahwa LH menampilkan perilaku yang cukup baik, tidak menunjukkan pelanggaran, mengikuti kelas dengan baik dan tidak terlambat datang ke kelas. LH mengikuti ibadah sholat Jumat bersama dengan temantemannya, dan hadir dalam setiap kegiatan di panti. Selanjutnya, Pembina menyampaikan bahwa SZ mulai berani untuk ikut berpartisipasi dalam kegiatan keagamaan yang akan diselenggarakan oleh panti. SZ mengikuti jadwal latihan dengan baik dan didampingi oleh instrukturnya.

Berdasarkan temuan dari penelitian ini, diketahui bahwa kedua subjek mengalami peningkatan psychological wellbeing setelah melakukan berbagai aktivitas dalam sesi-sesi well-being therapy. Hal ini sesuai dengan yang dikemukakan oleh Linley dan Joseph (2004) yang menyampaikan bahwa well-being therapy merupakan salah satu terapi yang dapat meningkatkan tingkat psychological wellbeing individu, sesuai dengan enam dimensi yang dikemukakan oleh Ryff (1989). Tujuan utama dari well-being therapy (WBT) ini adalah mengaktualisasikan kesehatan psikologis yang dapat dicapai dengan membantu klien untuk menyadari potensi yang sebenarnya dan mencapai keberfungsian secara optimal (Fava \& Ruini, 2004).

Selama berlangsungnya sesi, individu didorong untuk merasakan hal yang positif dari dirinya, merefleksikan kemampuankemampuannya, dan mengingat pengalaman-pengalaman yang positif. Proses ini membuat individu dapat lebih merasakan sisi positif dalam dirinya dan membuka pandangan serta wawasan tentang kehidupan dan dirinya secara lebih positif. Pemanfaatan kekuatan-kekuatan yang dimiliki oleh individu telah mendukung keberhasilan terapi. Situasi yang menyenangkan, komunikasi yang terbuka, kehadiran peneliti dalam 
memberikan dukungan yang diberikan dalam bentuk apresiasi dan feedback positif merupakan faktor-faktor yang mendorong kedua subjek mengalami peningkatan dalam penilaian keduanya terhadap psychological well-being yang dimiliki.

Selain itu, faktor lainnya yang menjadi pendukung keberhasilan dalam penerapan well-being therapy ini adalah kedua subjek menunjukkan adanya kesediaan untuk berubah dan memiliki harapan yang positif atas perubahan diri. Keinginan untuk berubah menjadi salah satu hal penting dalam mencapai tujuan penerapan suatu terapi. Kondisi ini membuat individu mau terbuka, menjadi lebih disiplin dalam proses terapi, mengerjakan tugas yang diberikan dengan sungguh-sungguh, dan tetap mempertahankan hal yang sudah berhasil diperoleh selama terapi.

\section{SIMPULAN DAN SARAN 5.1 Simpulan}

Berdasarkan hasil penelitian yang dilakukan, diketahui bahwa kedua subjek, LH dan SZ mengalami peningkatan skor psychological well-being dengan pengukuran yang menggunakan kuesioner sebelum dan setelah mengikuti enam sesi intervensi. Hasil analisis uji paired sample t-test juga menunjukkan bahwa kedua subjek mengalami perubahan yang signifikan setelah diberikan Well-being Therapy (WBT). Hasil pengukuran tersebut juga didukung oleh hasil wawancara kepada masing-masing subjek setelah mengikuti keenam sesi dari WBT ini. Hasil wawancara menunjukkan bahwa kedua subjek lebih mampu menilai dirinya secara positif, lebih memiliki gambaran tentang masa depannya, dan merasa lebih dapat mengembangkan diri.

Selanjutnya, pada saat dilakukan monitoring dan evaluasi dengan melakukan wawancara kepada pembina, diketahui bahwa kedua subjek sedikit demi sedikit mulai menunjukkan perubahan yang positif. Kedua subjek mulai menampilkan perilakuperilaku yang memenuhi aspek-aspek dari psychological well-being, antara lain mampu menerima dirinya, mandiri, memiliki hubungan positif dengan orang lain, memilih dan menentukan lingkungan, mengembangkan diri, dan memiliki tujuan di masa depan. Hal ini menunjukkan bahwa Well-Being Therapy (WBT) memiliki peranan dalam meningkatkan psychological well-being remaja yang tinggal di Panti Sosial Bina Remaja X.

\subsection{Saran}

\subsubsection{Saran untuk Penelitian Selanjutnya}

Berdasarkan hasil penelitian tersebut, terdapat beberapa saran yang dapat kepada penelitian selanjutnya, kepada para remaja yang telah menjadi subyek dalam penelitian ini, bagi pihak Panti Sosial Bina Remaja X, dan bagi perguruan tinggi. Penelitian selanjutnya diharapkan dapat menerapkan intervensi WBT ini dalam karakteristik subyek yang berbeda, sehingga dapat memiliki gambaran yang lebih luas dalam mengetahui penerapan lebih lanjut dari intervensi ini. Selain itu, pelaksanaan intervensi dapat divariasikan dengan kegiatan-kegiatan yang lebih interaktif, misalnya dikombinasikan dengan media gambar atau aktivitas permainan, sehingga menjadi lebih menarik dan tidak monoton pada penggunaan lembar kerja saja.

Selain itu, penerapan intervensi ini dapat dikembangkan untuk dilakukan secara kelompok, dengan melakukan aktivitas-aktivitas yang berkaitan dengan keenam dimensi dari psychological wellbeing, sehingga dapat membentuk support group bagi para remaja yang memiliki karakteristik tertentu. Pada penelitian selanjutnya, sebaiknya dapat menggunakan instrumen pengukuran psychological wellbeing yang telah diuji validitas dan reliabilitasnya pada kelompok sampel yang sesuai dengan karakteristik subyek penelitian, misalnya remaja di panti asuhan atau panti sosial.

\subsubsection{Saran bagi Pihak-pihak yang Berkepentingan}

Saran diberikan juga bagi kedua subyek, yaitu LH dan SZ, untuk dapat mempertahankan atau bahkan semakin meningkatkan psychological well-being yang dimiliki. Kedua subyek sebaiknya dapat terus berlatih untuk melihat segala 
sesuatu dari sisi yang positif. Subyek dapat mengubah pola pikir bahwa tinggal di panti bukanlah suatu kondisi yang buruk, tetapi merupakan kesempatan untuk belajar dan meningkatkan keterampilan untuk dapat membekali diri mempersiapkan masa depan. LH dan SZ juga dapat terus bersyukur atas hal-hal yang dimiliki, pencapaian yang telah dilalui, sehingga dapat lebih merasakan kebahagiaan dan memandang hidup secara lebih positif. Selain itu, LH dan SZ dapat berbagi cerita, perasaan dan pengalaman dengan teman atau dalam kelompok kecil, sehingga dapat memiliki interaksi yang baik dengan teman, merasakan mendapatkan dukungan dan kebersamaan dengan orang lain.

Jumlah remaja yang tinggal di panti tergolong banyak, sehingga pada dasarnya remaja-remaja lain di panti juga perlu mendapatkan penanganan yang dapat membantu mereka meningkatkan psychological well-being yang dimiliki. Oleh karena itu, terdapat beberapa saran yang dapat diberikan kepada pihak panti untuk dapat memberikan penanganan yang optimal bagi remaja sebagai warga binaan sosial, antara lain para pembina dapat memberikan apresiasi kepada para remaja yang menampilkan hal-hal positif. Para pembina juga dapat menunjukkan perhatian dan membangun komunikasi efektif dengan para remaja, misalnya dengan kegiatan sharing atau konsultasi individual, sehingga dapat membangun hubungan yang erat dengan para remaja, dan remaja merasa diperhatikan, diberi dukungan, dan memiliki kedekatan dengan pembina.

Pelaksanaan tes minat pada awal penerimaan warga binaan sosial yang telah dilakukan oleh satuan pelaksana pelayanan sosial dapat terus dikembangkan dan dilaksanakan, sehingga dapat terus membantu remaja yang membutuhkan arahan terkait pilihan jurusan yang sesuai dengan minatnya. Kesembilan pilihan jurusan yang telah ada, yaitu menjahit, salon, otomotif, las, service pendingin udara, service HP, computer, furniture, dan tata boga dapat terus dikembangkan, dan jika memungkinkan dapat juga ditambah dengan pilihan jurusan lainnya, misalnya seni lukis, membatik, percetakan, dan sebagainya.

Selain itu, para pembina juga dapat melibatkan diri menjadi agen perubahan bagi para remaja, misalnya dengan mengikuti pelatihan yang diberikan oleh tenaga psikolog atau professional lainnya di panti secara rutin, tentang topik-topik remaja dan penanganannya. Hal ini membuat pembina dapat melanjutkan penanganan secara berkala dan menerapkan pada remaja-remaja lainnya. Para pembina dapat juga mengikuti pelatihan yang dapat diaplikasikan dalam bentuk intervensi sosial, misalnya appreciative inquiry, diskusi kelompok, dan sebagainya.

Berdasarkan hasil penelitian yang diperoleh, maka perguruan tinggi dapat melakukan sosialisasi kepada mahasiswa, orangtua, praktisi, guru, ataupun masyarakat bahwa psychological well-being adalah salah satu hal yang penting dalam hidup, agar individu mampu bertahan dan menghadapi permasalahan secara lebih positif, mengingat semakin hari semakin banyak permasalahan yang dialami oleh masyrakat, misalnya masalah ekonomi, masalah keluarga, dan masalah-masalah sosial lainnya. Psychological well-being dapat membuat seseorang merasa bahagia dan berusaha menjalani kehidupan dengan sebaik-baiknya. Sosialisasi ini dapat dilakukan dalam bentuk seminar umum atau dalam bentuk penyampaian materi pada mata kuliah tertentu, misalnya Psikologi Perkembangan, Psikologi Positif, ataupun Character Building.

\section{DAFTAR PUSTAKA}

Fava, G. A., \& Ruini, C. (2003). Development and characteristic of a well-being enhancing psychotherapeutic strategy: wellbeing therapy. Journal of Behavior Therapy and Experimental Psychiatry. Vol 34. 45-63.

Fava, G. A., \& Ruini, C. (2004). Clinical applications of well-being therapy: Positive Psychology in practice. 
Edited by P.A. Linley \& S. Joseph. NJ: John Wiley \& Sons.

Fava, G. A. \& Ruini, C. (2014). Increasing psychological well-being in clinical and educational settings: Interventions and cultural context. Springer Science + Business Media Dordrecht. DOI 10.1007/978-94-0178669-0_1.

Fava, G. A., \& Tomba, E. (2009). Increasing psychological well being and resilience by psychotherapeutic methods. Journal of Personality. Vol 77 (6). 1904 - 1934.

Folk-Williams, John. (2013). How wellbeing therapy works. http://www.storiedmind.com. Diakses tanggal 26 Oktober 2016.

Glosarium Penyelenggaraan Kesejahteraan Sosial. (2009). Diunduh dari http://www.kemsos.go.id/modules.ph $\mathrm{p}$ ?name $=$ glosariumkesos \&letter $=\mathrm{p}$

Gunarsa, Y. S. D. \& Gunarsa, S. D. (2012). Psikologi Remaja. Jakarta : Penerbit Libri.

Haryanto, R., \& Suyasa, P. T. Y. S. (2007). Persepsi terhadap job characteristic model, psychological well-being dan performance (studi pada karyawan PT. X). Phronesis Jurnal Ilmiah Psikologi Industri dan Organisasi. Vol 9 (1). 67-92.

Handler, D. (2008). Personal growth and behavior. Edited by Karen G. Duffy. Dubuque : McGraw-Hill.

Holland, A. L. (2007). Conseling in communication disorders: A Wellness Perspective. Oxdordshire: Plural Publishing.

Linley, P. A., \& Joseph, S. (2004). Positive Psychology in Practice. New Jersey : John Wiley and Son, Inc.
Ryff, Carol. D. (1989). Happiness is everything, or is it? Explorationson the meaning of psychological wellbeing. Journal of Personality and Social Psychology. Vol 57 (6). 10691081.

Santrock, J. W. (2012). A Topical Approach to Life Span Development $6^{\text {th }}$ edition. New York: McGraw-Hill Company, Inc.

Sari, R. B. (2015). Tingkat Psychological Well-being pada Remaja di Panti Sosial Bina Remaja Yogyakarta. EJournal Bimbingan dan Konseling. Edisi 12 tahun ke-4. Hal 1-11

Sarwono, Sarlito. W. (2015). Psikologi Remaja. Jakarta: Rajawali Pers.

Seniati, L., Yulianto, A., \& Setiadi, B. N. (2011). Psikologi Eksperimen. Jakarta: Indeks.

Septiani, N. \& Utoyo, D. B. (2013). Gambaran Psychological Well-being pada remaja yang tinggal di panti asuhan. Jurnal Skripsi. Fakultas Psikologi Universitas Indonesia.

Steinberg, L. (2011). Adolescence (9th ed.). NY: McGraw-Hill.

Vos A.S., Strydom, H., Fouché C.B. \& Delport C.S.L. (2011). Research at the grass roots for the social sciences and human service professions $4^{\text {th }} \mathrm{ed}$. Pretoria: JL Van Schaik Publishers.

Winefield, H R., Gill, T K., Taylor, A W., \& Pilkington, R M. (2012). Psychological well-being and psychological distress : is it necessary to measure both? Psychological of Well-Being, 1-14. 